\title{
Higher anti-depressant dose and major adverse outcomes in moderate chronic kidney disease: a retrospective population-based study
}

Varun Dev ${ }^{1}$, Stephanie N Dixon 1,2,3,4, Jamie L Fleet ${ }^{2}$, Sonja Gandhi ${ }^{1,2,3}$, Tara Gomes ${ }^{4,5,6}$, Ziv Harel ${ }^{7}$, Arsh K Jain ${ }^{1,2,3}$, Salimah Z Shariff ${ }^{1,4}$, Davy Tawadrous ${ }^{1,2}$, Matthew A Weir ${ }^{1,2,3}$ and Amit X Garg $1,2,3,4,8^{*}$

\begin{abstract}
Background: Many older patients have chronic kidney disease (CKD), and a lower dose of anti-depressants paroxetine, mirtazapine and venlafaxine is recommended in patients with CKD to prevent drug accumulation from reduced elimination. Using information available in large population-based healthcare administrative databases, we conducted this study to determine if ignoring the recommendation and prescribing a higher versus lower dose of anti-depressants associates with a higher risk of adverse events.

Methods: We conducted a population-based cohort study to describe the 30-day risk of delirium in older adults who initiated a higher vs. lower dose of these three anti-depressants in routine care. We defined delirium using the best proxy available in our data sources - hospitalization with an urgent head computed tomography (CT) scan. We determined if CKD status modified the association between anti-depressant dose and outcome, and examined the secondary outcome of 30 day all-cause mortality. We used multivariable logistic regression analyses to estimate adjusted odds ratios (relative risk (RR)) and 95\% confidence intervals.

Results: We identified adults (mean age 75) in Ontario who started a new study anti-depressant at a higher dose $(n=36,651 ; 31 \%)$ or lower dose $(n=81,160 ; 69 \%)$. Initiating a higher vs. lower dose was not associated with an increased risk of hospitalization with head CT (1.09\% vs. 1.27\% (adjusted RR 0.90; $95 \% \mathrm{Cl}, 0.80$ to 1.02), but was associated with a lower risk of all-cause mortality $(0.76 \%$ vs. $0.97 \%$ RR $0.82 ; 95 \% \mathrm{Cl}, 0.71$ to 0.95$)$. Neither of these relative risks were modified by the presence of CKD ( $p=0.16,0.68$, respectively).

Conclusions: We did not observe an increase in two adverse outcomes when study anti-depressants were initiated at a higher dose in elderly patients with moderate CKD. Contrary to our hypothesis, the 30-day risk of mortality was lower when a higher versus lower dose of anti-depressant was initiated in these patients, a finding which requires corroboration and further study.
\end{abstract}

Keywords: Anti-depressant, Delirium, Aged, Chronic renal insufficiency, Cohort studies, Risk

\section{Background}

Anti-depressants are among the most widely prescribed medications worldwide and depression is the most common mental health problem in the elderly [1-5]. The prevalence of depression in elderly individuals with chronic kidney disease (CKD) is estimated at $15-30 \%$ [6]. Older adults have age-related changes in drug

\footnotetext{
* Correspondence: amit.garg@lhsc.on.ca

${ }^{1}$ Schulich School of Medicine, Western University, London, Canada

Division of Nephrology, Western University, London, Ontario, Canada

Full list of author information is available at the end of the article
}

metabolism that can increase their risk of adverse drug effects, a finding particularly true for many anti-depressants [7-9]. Up to $30 \%$ of these older adults also have CKD, which can cause drug accumulation through reduced elimination, further increasing the risk of adverse events $[10,11]$. A number of pharmacokinetic studies have demonstrated that the serum half lives of three common antidepressants (paroxetine, mirtazapine or venlafaxine) are significantly prolonged in individuals with CKD [6,12-14]. Additionally, several case reports link the use of these three anti-depressants to delirium, a state of acute 
confusion that can lead to hospitalization and death [15-18]. Thus, in CKD, use of lower doses of these three anti-depressants is recommended in drug prescribing references (recommendations summarized in Table 1). Using information available in large population-based healthcare administrative databases, we conducted this study in older adults to determine if ignoring the recommendation and initiating a higher vs. lower dose of three study antidepressants (paroxetine, mirtazapine or venlafaxine) associates with a higher risk of adverse events. The two outcomes assessed in our data sources were 30-day risk of delirium (assessed through a proxy of hospitalization with an urgent head computed tomography (CT) scan) and mortality. We also examined if the presence of CKD modified the association between anti-depressant dose (higher v. lower) and outcome.

\section{Methods}

\section{Setting and study design}

Residents of the province of Ontario, Canada have universal access to hospital care and physician services. Those 65 years of age or older, representing approximately 2 million individuals in 2012, also have universal prescription coverage [25]. All health care encounters in Ontario are recorded in linked, de-identified databases at the Institute for Clinical Evaluative Sciences (ICES). We conducted a retrospective, population-based cohort study using six of these healthcare databases. We conducted this study according to a pre-specified protocol that was approved by the research ethics board at Sunnybrook Health Sciences Centre (Toronto, Canada). The reporting of this study follows guidelines for observational studies (detailed in Additional file 1: Figure S1) [26].

\section{Data sources}

We ascertained baseline characteristics, drug use and dose, and outcome data using six linked healthcare databases.
Demographic and vital status information on all Ontario residents who have ever been issued a health card is recorded in the Ontario Registered Persons Database (RPDB). Detailed diagnostic and procedural information on all hospital admissions and emergency room visits is recorded in the Canadian Institute for Health Information Discharge Abstract Database (CIHI-DAD) and the National Ambulatory Care Reporting System (NACRS), respectively. Health claims for inpatient and outpatient physician services are recorded in the Ontario Health Insurance Plan database (OHIP). Outpatient prescription drug information including the dispensing date, quantity of pills, dose, and number of days supplied is accurately recorded in the Ontario Drug Benefit Program database (ODB), with an error rate less than 1\% [27]. Lastly, the ICES Physician Database (IPDB) contains information on all physicians in Ontario such as sub-specialty, education, location and demographics.

Among a subpopulation of patients with prescriptions filled in Southwestern Ontario, we also obtained baseline serum creatinine values from two linked laboratory datasets: Gamma-Dynacare, a large outpatient provincial laboratory provider and Cerner $^{\circ}$ (Kansas City, Missouri, USA), an electronic medical record database containing inpatient, outpatient, and emergency department laboratory values for 12 hospitals in Southwestern Ontario [28]. The most recent serum creatinine was obtained in the year prior to the study anti-depressant prescription (median 94 days prior to the prescription). These data sources have been used previously to study drug safety [29-31]. With the exception of anti-depressant prescriber specialty and income quintile (missing in 13.5\% and $0.3 \%$ of patients, respectively), the databases were complete for all variables used in this study.

\section{Patients}

We established a cohort of all older adults in Ontario who had evidence of a new outpatient prescription for a

Table 1 Anti-depressant dosing in popular drug prescribing references

\begin{tabular}{|c|c|c|c|c|c|}
\hline & $\begin{array}{l}\text { Higher dose } \\
(\mathrm{mg} / \text { day })^{*}\end{array}$ & $\begin{array}{l}\text { Lower dose } \\
(\mathrm{mg} / \text { day })^{*}\end{array}$ & $\begin{array}{l}\text { UpToDate } \\
\text { recommendation [19-21] }\end{array}$ & $\begin{array}{l}\text { Compendium of pharmaceuticals } \\
\text { and specialties [22-24] }\end{array}$ & Systematic review [6] \\
\hline \multirow[t]{2}{*}{ Paroxetine } & \multirow[t]{2}{*}{$>20$} & \multirow[t]{2}{*}{$\leq 20$} & $\cdot 20$ - 50 mg/day & $\cdot 20$ - 50 mg/day & $\cdot 20$ - 50 mg/day \\
\hline & & & $\begin{array}{l}\text { - Reduce by } 50 \% \text { with } \\
\mathrm{CrCl}<30 \mathrm{ml} / \mathrm{min}\end{array}$ & $\begin{array}{l}\text { - Initiate at } 10 \mathrm{mg} / \text { day with } \\
\mathrm{CrCl}<40 \mathrm{ml} / \mathrm{min}\end{array}$ & $\begin{array}{l}\text { - Initiate at } 10 \mathrm{mg} / \text { day with } \\
\text { eGFR }<60 \mathrm{ml} / \mathrm{min}\end{array}$ \\
\hline \multirow[t]{3}{*}{ Mirtazapine } & \multirow[t]{3}{*}{$>20$} & \multirow[t]{3}{*}{$\leq 20$} & $\cdot 15$ - 45 mg/day & • 15 - 45 mg/day & $\cdot 15$ - 45 mg/day \\
\hline & & & \multirow{2}{*}{$\begin{array}{l}\text { - Use with caution with } \\
\mathrm{CrCl}<40 \mathrm{ml} / \mathrm{min}\end{array}$} & \multirow[t]{2}{*}{ - Use with caution } & - Use with caution \\
\hline & & & & & $\begin{array}{l}\text { - Initiate at } 15 \text { mg/day with } \\
\text { eGFR }<30 \mathrm{ml} / \mathrm{min}\end{array}$ \\
\hline \multirow[t]{3}{*}{ Venlafaxine } & \multirow[t]{3}{*}{$>37.5$} & \multirow[t]{3}{*}{$\leq 37.5$} & • 75 - 225 mg/day & • 75 - 225 mg/day & • 75 - 225 mg/day \\
\hline & & & \multirow[t]{2}{*}{$\begin{array}{l}\text { - Reduce by } 25-50 \% \text { with } \\
\mathrm{CrCl} 10-70 \mathrm{ml} / \mathrm{min}\end{array}$} & $\begin{array}{l}\text { - Reduce by } 25-50 \% \text { with } \\
\text { GFR } 10-70 \mathrm{ml} / \mathrm{min}\end{array}$ & \multirow[t]{2}{*}{$\begin{array}{l}\text { - Reduce to } 37.5 \mathrm{mg} / \text { day with } \\
\text { eGFR }<30 \mathrm{ml} / \mathrm{min}\end{array}$} \\
\hline & & & & - Initiate at 37.5 mg/day & \\
\hline
\end{tabular}


study anti-depressant (defined as no prescriptions for any type of study or non-study anti-depressant in the prior six months) between April ${ }^{\text {st }}, 2002$ and December $31^{\text {st }} 2011(\mathrm{n}=169,435)$. The three study anti-depressants were paroxetine, mirtazapine, and venlafaxine. Patients with multiple eligible prescriptions could only enter the cohort once, and the date of anti-depressant initiation served as the patient's index date (cohort entry date; start of follow-up). We assessed baseline demographic characteristics, co-morbid conditions (5 years prior to index date) and concurrent drug therapy (180 days prior to index date) among all individuals. We excluded the following anti-depressant users from the analysis: those in the first year of eligibility for prescription drug coverage (age 65 years) to avoid incomplete medication records $(n=12,588)$; those who were discharged from hospital in the two days before their index date to ensure that prescriptions were new outpatient anti-depressant prescriptions (as in Ontario, patients continuing an antidepressant treatment initiated in hospital would have their oral outpatient antidepressant prescription dispensed on the same day or the day after hospital discharge) ( $n=3,833)$; those living in long-term care facilities because some residents chronically experience bouts of confusion $(n=30,360)$; those with end-stage renal disease since treatments such as dialysis alter anti-depressant pharmacokinetics unpredictably [14] $(\mathrm{n}=1,522)$; and those who received more than one type of anti-depressant on their index date to allow comparison of mutually exclusive exposure groups $(\mathrm{n}=3,321)$. A total of 117,811 patients were included in the final analysis.

We identified individuals with moderate CKD using an algorithm of diagnosis codes validated in our region for older adults [32]. The algorithm identifies a group of patients with a low GFR by the Chronic Kidney Disease Epidemiology Collaboration (CKD-EPI) formula. It identified patients with a median estimated glomerular filtration rate (eGFR) of $38 \mathrm{~mL} / \mathrm{min}$ per $1.73 \mathrm{~m}^{2}$ (interquartile range 27 to 52), whereas its absence identified patients with a median eGFR of $69 \mathrm{~mL} / \mathrm{min}$ per $1.73 \mathrm{~m}^{2}$ (interquartile range 56 to 82 ).

\section{Anti-depressant dose}

To align with recommendations in drug prescribing references, a higher dose of anti-depressant was defined as $>20 \mathrm{mg} /$ day of paroxetine, $>20 \mathrm{mg} /$ day of mirtazapine, or $>37.5 \mathrm{mg} /$ day of venlafaxine (Table 1). A lower dose of anti-depressant was defined as $\leq 20 \mathrm{mg} /$ day of paroxetine, $\leq 20 \mathrm{mg} /$ day of mirtazapine, or $\leq 37.5 \mathrm{mg} /$ day of venlafaxine (Table 1$)$.

\section{Outcomes}

As most reported anti-depressant related delirium occurs within the first few weeks of drug initiation, we followed all individuals for 30 days after first antidepressant use for two pre-specified outcomes [33]. Our primary outcome was hospitalization with evidence of an urgent head CT scan. We used this as a proxy for the presence of acute central nervous system disturbance (i.e. delirium), as many patients in Ontario undergo such diagnostic imaging when presenting to hospital with acute confusion. Unlike diagnostic codes for acute delirium, the receipt of a head CT scan is well coded in our data sources because they are associated with physician reimbursement [34]. To focus on urgent imaging conducted for acute reasons at the time of hospital admission, we only considered head CT scans performed in the first five days of a hospital admission, or in the emergency department assessment preceding the hospital admission. We expected urgent head CT scans conducted for reasons unrelated to antidepressant dosing (e.g. stroke, headache) to occur at a similar frequency in higher and lower dose groups, not impacting estimates of difference in risk between the two groups. Our secondary outcome was all-cause mortality which is well coded in our data sources [35].

\section{Statistical analysis}

We compared baseline characteristics between those prescribed higher $v s$. lower daily doses of study antidepressants using standardized differences. This metric describes differences between group means relative to the pooled standard deviation and indicates a meaningful difference if greater than $10 \%$ [36]. We used multivariable logistic regression analyses (PROC LOGISTIC; SAS Institute, Cary, North Carolina) to estimate adjusted odds ratios and $95 \%$ confidence intervals. We adjusted for 15 potential confounders: antidepressant type, age, sex, year of cohort entry, modified Charlson score (a comorbidity index), and concurrent medication use (anticonvulsants, gabapentin, antipsychotics, barbiturates, benzodiazepines, histamine2-receptor antagonists, dopamine agonists, muscle relaxants, opioids and overactive bladder medications). Outcomes are expressed with patients receiving a lower dose of anti-depressant as the referent group. We then tested for statistical interactions to determine whether the association between antidepressant drug dose (higher vs. lower) and outcome was modified by the presence of moderate CKD. All odds ratios were interpreted as relative risks (appropriate given the low incidences observed). We conducted all statistical analyses using SAS, version 9.3.

\section{Results}

The study included 117,811 eligible older adults in routine outpatient care who were dispensed a new oral study anti-depressant (patient selection diagram presented in Additional file 1: Figure S1). A total of 36,651 patients (31\%) were initiated on a higher anti-depressant 
Table 2 Baseline characteristics by anti-depressant dose

\begin{tabular}{|c|c|c|c|}
\hline & Higher dose & Lower dose & Standardized \\
\hline & $N=36,651$ & $N=81,160$ & \\
\hline Anti-depressant type, $n$ (\%) & & & \\
\hline Paroxetine & $4,216(11.5)$ & $41,889(51.6)$ & 0.96 \\
\hline Mirtazapine & $9,531(26.0)$ & $15,101(18.6)$ & 0.18 \\
\hline Venlafaxine & $22,904(62.5)$ & $24,170(29.8)$ & 0.69 \\
\hline Demographics & & & \\
\hline Age, years, mean (SD) & $73.7(6.8)$ & $75.6(5.8)$ & 0.29 \\
\hline Women, $n$ (\%) & $22,472(61.3)$ & $54,631(67.3)$ & 0.13 \\
\hline Year of cohort entry, $n$ (\%) & & & \\
\hline $2002-2005$ & $16,434(44.8)$ & $4,2770(52.7)$ & 0.16 \\
\hline 2006-2009 & $14,661(40.0)$ & 2,7984 (34.5) & 0.11 \\
\hline 2010-2011 & $5,556(15.2)$ & $10,406(12.8)$ & 0.07 \\
\hline Income quintile, $n$ (\%) & & & \\
\hline First (lowest) & $7,663(20.9)$ & $16,725(20.6)$ & 0.01 \\
\hline Second & $7,552(20.6)$ & $17,627(21.7)$ & 0.03 \\
\hline Third (middle) & $7,034(19.20$ & $16,003(19.7)$ & 0.01 \\
\hline Fourth & $7,118(19.4)$ & $15,226(18.8)$ & 0.02 \\
\hline Fifth (highest) & $7,142(19.5)$ & $15,327(18.9)$ & 0.02 \\
\hline Missing & $142(0.4)$ & $252(0.3)$ & 0.01 \\
\hline Rural Location, $n(\%)$ & $5,386(14.7)$ & $10,943(13.5)$ & 0.03 \\
\hline Modified Charlson score ${ }^{\mp}, n$ (\%) & & & \\
\hline 0 or no hospitalization & $25,360(69.2)$ & $56,063(69.0)$ & 0.00 \\
\hline 1 & $4,263(11.6)$ & $9,548(11.7)$ & 0.00 \\
\hline 2 & $3,514(9.6)$ & $7,571(9.3)$ & 0.01 \\
\hline$\geq 3$ & 3,514 (9.6) & $8,005(9.9)$ & 0.01 \\
\hline Co-morbidities ${ }^{\mp}, n(\%)$ & & & \\
\hline Chronic liver disease & $1,348(3.7)$ & $2,970(3.7)$ & 0.00 \\
\hline Chronic kidney disease $^{*}$ & $1,609(4.4)$ & $3,772(4.7)$ & 0.01 \\
\hline Chronic obstructive pulmonary disease & $1,849(5.0)$ & $4,389(5.4)$ & 0.02 \\
\hline Coronary artery disease & $12,951(35.3)$ & $31,350(38.6)$ & 0.07 \\
\hline Heart failure & $4,133(11.3)$ & $10,715(13.2)$ & 0.06 \\
\hline Stroke/Transient ischemic attack & $1,148(3.1)$ & $2,625(3.2)$ & 0.01 \\
\hline Diabetes mellitus (on medication) $^{+}$ & $5,878(16.0)$ & $12,203(15.0)$ & 0.03 \\
\hline Medication ${ }^{*}, n(\%)$ & & & \\
\hline Anticonvulsants & $3,728(10.2)$ & $6,574(8.1)$ & 0.07 \\
\hline Gabapentin & $363(1.0)$ & $525(0.7)$ & 0.04 \\
\hline Antipsychotics & 2,499 (6.8) & $3,752(4.6)$ & 0.09 \\
\hline Barbiturates & $89(0.2)$ & $163(0.2)$ & 0.01 \\
\hline Benzodiazepines & $15,736(42.9)$ & $35,681(44.0)$ & 0.02 \\
\hline Histamine2-receptor antagonists & $3,417(9.3)$ & $9,764(12.0)$ & 0.09 \\
\hline Dopamine agonists & $298(0.8)$ & $517(0.6)$ & 0.02 \\
\hline Muscle relaxants & $311(0.9)$ & $564(0.7)$ & 0.02 \\
\hline Opioids & $10,408(28.4)$ & $21,632(26.7)$ & 0.04 \\
\hline Overactive bladder medications & $1,424(3.9)$ & $2,992(3.7)$ & 0.01 \\
\hline
\end{tabular}


Table 2 Baseline characteristics by anti-depressant dose (Continued)

\begin{tabular}{llll}
\hline Prescribing physician, $\boldsymbol{n}(\%)$ & & & \\
General practitioner & $27,884(76.1)$ & $62,622(77.2)$ & 0.03 \\
Internist & $251(0.7)$ & $669(0.8)$ & 0.02 \\
Neurologist & $179(0.5)$ & $408(0.5)$ & 0.00 \\
Other & $3,514(9.6)$ & $6,354(7.8)$ & 0.06 \\
Missing & $4,823(13.2)$ & $11,107(13.7)$ & 0.02 \\
\hline
\end{tabular}

${ }^{\mathrm{E}}$ Co-morbidities were assessed in the five years prior to the index date using International Classification of Diseases $9^{\text {th }}$ revision (ICD-9) and $10^{\text {th }}$ revision (ICD-10) codes.

${ }^{\mp}$ Assessed with an algorithm using diagnosis codes from hospitalizations in the five years prior; patients with no hospitalizations during this period were given a value of zero.

*Identified individuals with CKD using an algorithm of diagnosis codes validated in our region for older adults [32].

The algorithm identified patients with a median estimated glomerular filtration rate (eGFR) of $38 \mathrm{~mL} / \mathrm{min}$ per $1.73 \mathrm{~m}^{2}$ (interquartile range 27 to 52 ), whereas its

absence identified patients with a median eGFR of $69 \mathrm{~mL} / \mathrm{min}$ per $1.73 \mathrm{~m}^{2}$ (interquartile range 56 to 82 ).

${ }^{9}$ Coronary artery disease includes receipt of coronary artery bypass graft surgery, percutaneous coronary intervention and diagnoses of angina.

${ }^{*}$ Medication use was assessed in the 180 days prior to the index date.

+Diabetic medications include oral hypoglycemics and insulin.

dose, and 81,160 patients (69\%) were initiated on a lower anti-depressant dose. Most prescriptions were written by a primary care physician (76.8\%). There was no significant difference in 20 of the 25 measured baseline characteristics between the higher and lower anti-depressant dose groups (Table 2). However, compared to those in the lower dose group, patients in the higher dose group were more likely to be prescribed mirtazapine and venlafaxine $(26.0 \%$ vs. $18.6 \%$, and $62.5 \%$ vs. $29.8 \%$, respectively), were more likely to be younger (mean 73.7 years vs. 75.6 years), were more likely to enter the cohort between the years 2006 to 2009 (40.0\% vs. 34.5\%), were less likely to enter the cohort between the years 2002 to 2005 (44.8\% vs. 52.7\%) and were less likely to be women (61.3\% vs. 67.3\%).

\section{0-day hospitalization with urgent head Computed Tomography (CT) scan}

Initiation of a higher vs. lower anti-depressant dose was associated with a lower risk of hospitalization with head CT scan (Table 3; 400/36,651 [1.09\%] vs. 1,033/81,160 [1.27\%], unadjusted relative risk 0.86 [95\% CI 0.76 to 0.96]). After adjusting for 15 potential confounders the association was no longer significant (Table 3; adjusted relative risk 0.90 [95\% CI 0.80 to 1.02]). The association was not appreciably different in patients with and without moderate CKD (when the presence of this condition was assessed with diagnosis codes; Figure 1; interaction $P$ value $=0.16$ ). The association was also not appreciably different in patients with and without moderate CKD when examined separately by each of the three antidepressant drugs (recognizing stratifying the results in this way resulted in smaller sample sizes and wider confidence intervals; Figure 2).

\section{0-day all-cause mortality}

Initiation of a higher $v s$. lower anti-depressant dose was associated with a lower risk of 30-day all-cause mortality (Table 3; 278/36,651 [0.76\%] vs. 791/81,160 [0.97\%], absolute risk reduction $0.22 \%$ [ $95 \% \mathrm{CI} 0.10 \%$ to $0.33 \%]$, unadjusted relative risk 0.78 [95\% CI 0.68 to 0.89$]$ ]). Adjusting for 15 potential confounders had no appreciable impact on this observed association (adjusted relative risk 0.82 [95\% CI 0.71 to 0.95 ; Table 3). The association was not appreciably different in patients with and without moderate CKD (when the presence of this condition was assessed with diagnosis codes; Figure 1; interaction $P$ value $=0.96$ ). The association was also not appreciably different in patients with and without moderate CKD when examined separately by each of the three anti-depressant drugs (Figure 2).

Table 3 Association between anti-depressant dose and 30-day outcomes

\begin{tabular}{|c|c|c|c|c|c|}
\hline & \multicolumn{2}{|c|}{ Number of events, $n$ (\%) } & \multirow{3}{*}{$\begin{array}{l}\text { Relative risk } \\
\text { (Unadjusted) } \\
(95 \% \mathrm{Cl})\end{array}$} & \multirow{3}{*}{$\begin{array}{l}\text { Relative risk } \\
\text { (Adjusted) } \\
(95 \% \mathrm{CI})^{¥}\end{array}$} & \multirow{3}{*}{$\begin{array}{l}\text { Absolute risk } \\
\text { reduction (\%) } \\
(95 \% \mathrm{Cl})\end{array}$} \\
\hline & Higher dose $e^{£}$ & Lower dose" & & & \\
\hline & $N=36,651$ & $N=81,160$ & & & \\
\hline Hospital admission with head CT scan & $400(1.09)$ & $1,033(1.27)$ & $0.86(0.76-0.96)$ & $0.90(0.80-1.02)$ & $(\ldots)$ \\
\hline All-cause mortality & $278(0.76)$ & $791(0.97)$ & $0.78(0.68-0.89)$ & $0.82(0.71-0.95)$ & $0.22(0.10-0.33)$ \\
\hline
\end{tabular}

${ }^{E}$ Higher dose of anti-depressant defined as $>20 \mathrm{mg} /$ day of paroxetine, $>20 \mathrm{mg} /$ day of mirtazapine, or $>37.5 \mathrm{mg} /$ day of venlafaxine.

"Lower dose of anti-depressant defined as $\leq 20 \mathrm{mg} /$ day of paroxetine, $\leq 20 \mathrm{mg} /$ day of mirtazapine, or $\leq 37.5 \mathrm{mg} / \mathrm{day}$ of venlafaxine.

${ }^{¥}$ Adjusted for 15 covariates (see Methods).

(...) Absolute risk difference was not calculated as adjusted relative risk was not statistically significant for this outcome.

Patients prescribed the lower anti-depressant dose served as the referent group.

Abbreviations: Cl confidence interval, CT computed tomography. 


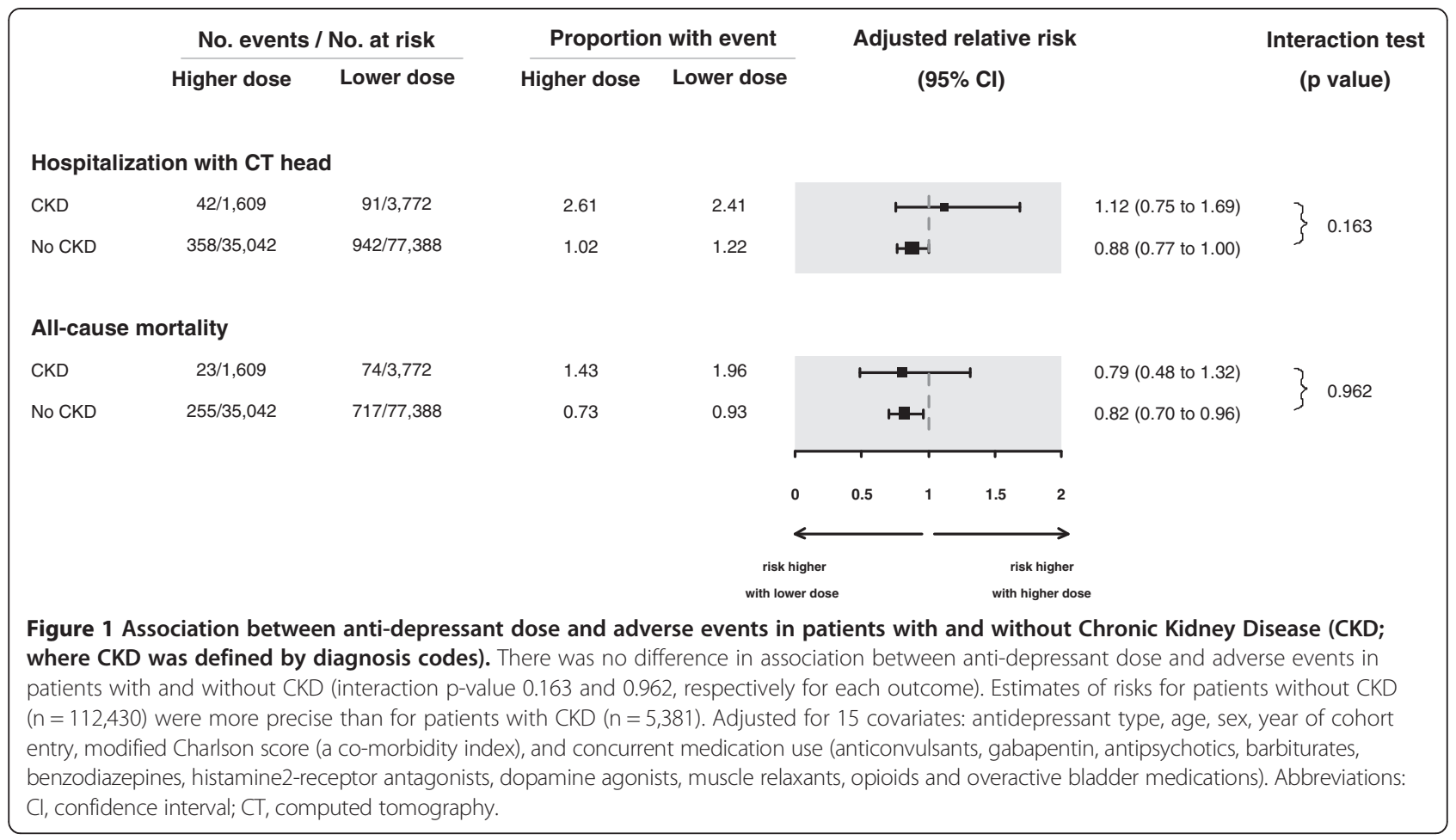

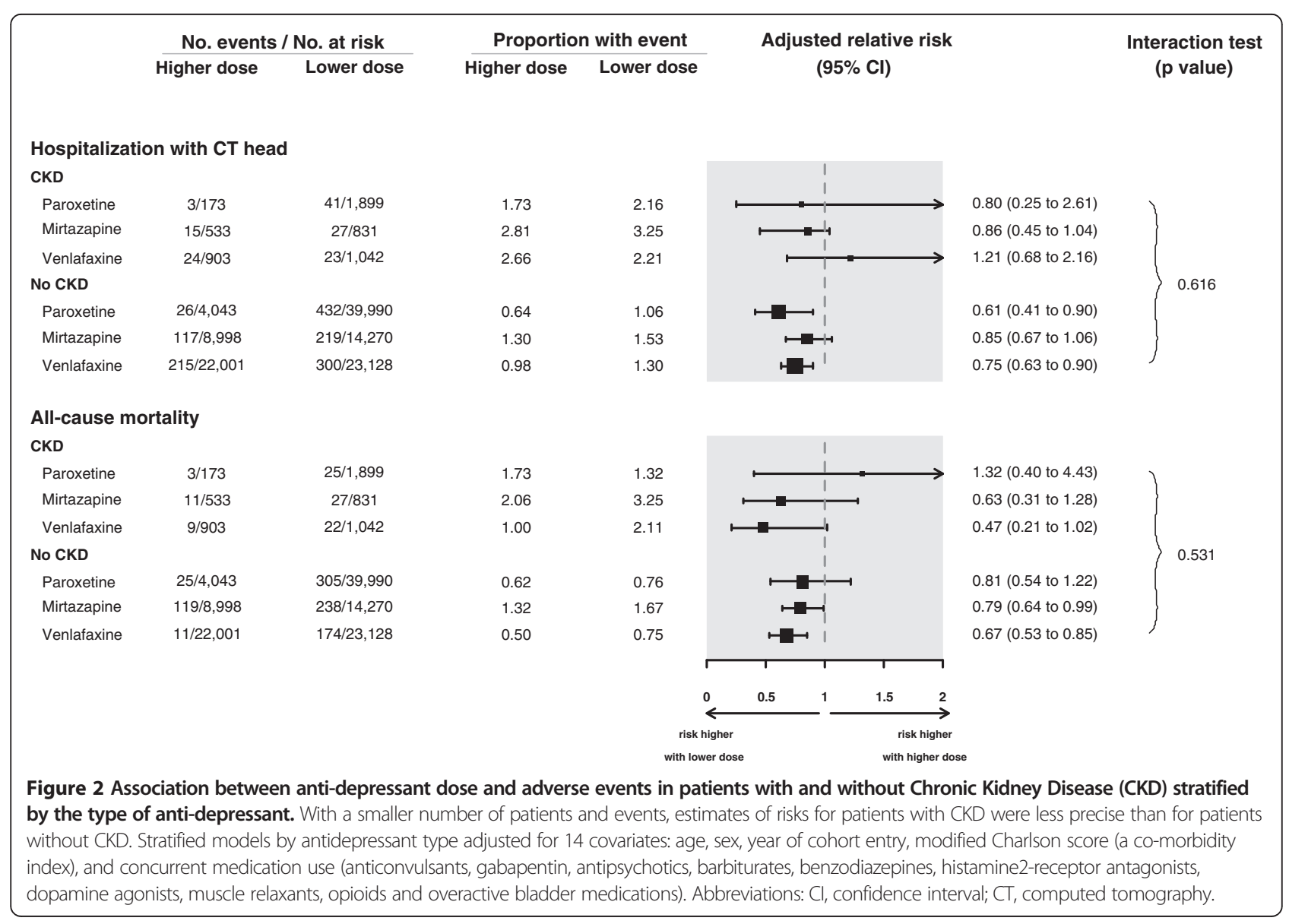




\section{Additional analyses}

We repeated our analysis in a subpopulation of older adults with baseline serum creatinine values $(n=24,641)$ comparing a higher $v s$. lower anti-depressant dose and each of our two outcomes. In this analysis the clinically important threshold used to define moderate CKD was an eGFR $<45 \mathrm{~mL} / \mathrm{min}$ per $1.73 \mathrm{~m}^{2}$ (as higher eGFR thresholds ( 45 to $60 \mathrm{~mL} / \mathrm{min}$ per $1.73 \mathrm{~m}^{2}$ ) may not identify substantial CKD in the elderly, and choosing a lower eGFR threshold $\left(<30 \mathrm{~mL} / \mathrm{min}\right.$ per $\left.1.73 \mathrm{~m}^{2}\right)$ meant less patients $(\mathrm{n}=587$ for this analysis)). Results are presented in Figure 3. Point estimates of the relative risk of a higher vs. lower anti-depressant dose and outcomes of head $\mathrm{CT}$ and all-cause mortality were all below a value of 1 in patients with and without a baseline eGFR value $<45 \mathrm{~mL} / \mathrm{min}$ per $1.73 \mathrm{~m}^{2}$. The association was not appreciably different in those with and without moderate CKD (Figure 3; interaction $P$ value $=0.73$ and 0.19 for each outcome, respectively).

In the primary cohort we considered the outcome of hospitalization using diagnostic codes for delirium (recognizing the coding for this outcome is insensitive and underestimates events but was expected not to operate differently in the two anti-depressant dose groups). Initiation of a higher $v s$. lower anti-depressant dose was not associated with a difference in risk of hospitalization with delirium $(43 / 36,651$ [0.16\%] vs. 126/81,160 [0.12\%], unadjusted relative risk 0.76 [95\% CI 0.53 to 1.07]). The association was not different in patients with and without moderate CKD (interaction $P$ value $=0.75$ ).

\section{Discussion}

We report the 30-day risk of two major adverse events as assessed in large healthcare administrative databases in older adults who initiated a higher $v$ s. lower dose of one of three common anti-depressants used in routine outpatient care. Contrary to our expectation, compared to a lower dose, initiation of a higher dose of antidepressant was associated with a lower 30-day risk of all-cause mortality. This association appeared similar in patients with and without moderate CKD, although estimates in patients with CKD were less precise. There was no association between the anti-depressant dose and the risk of hospitalization with urgent neuroimaging, an extreme outcome in the spectrum of delirium.

It is well established that older individuals are more prone to adverse drug reactions $[8,9,33]$. We hypothesized that the presence of moderate CKD would make older adults particularly vulnerable to toxicity from higher doses of three study anti-depressants that have been shown to accumulate in CKD (paroxetine, mirtazapine, venlafaxine). The data supporting dose reductions of these anti-depressants comes from pharmacokinetic studies and case studies [6,12]. To our knowledge, our

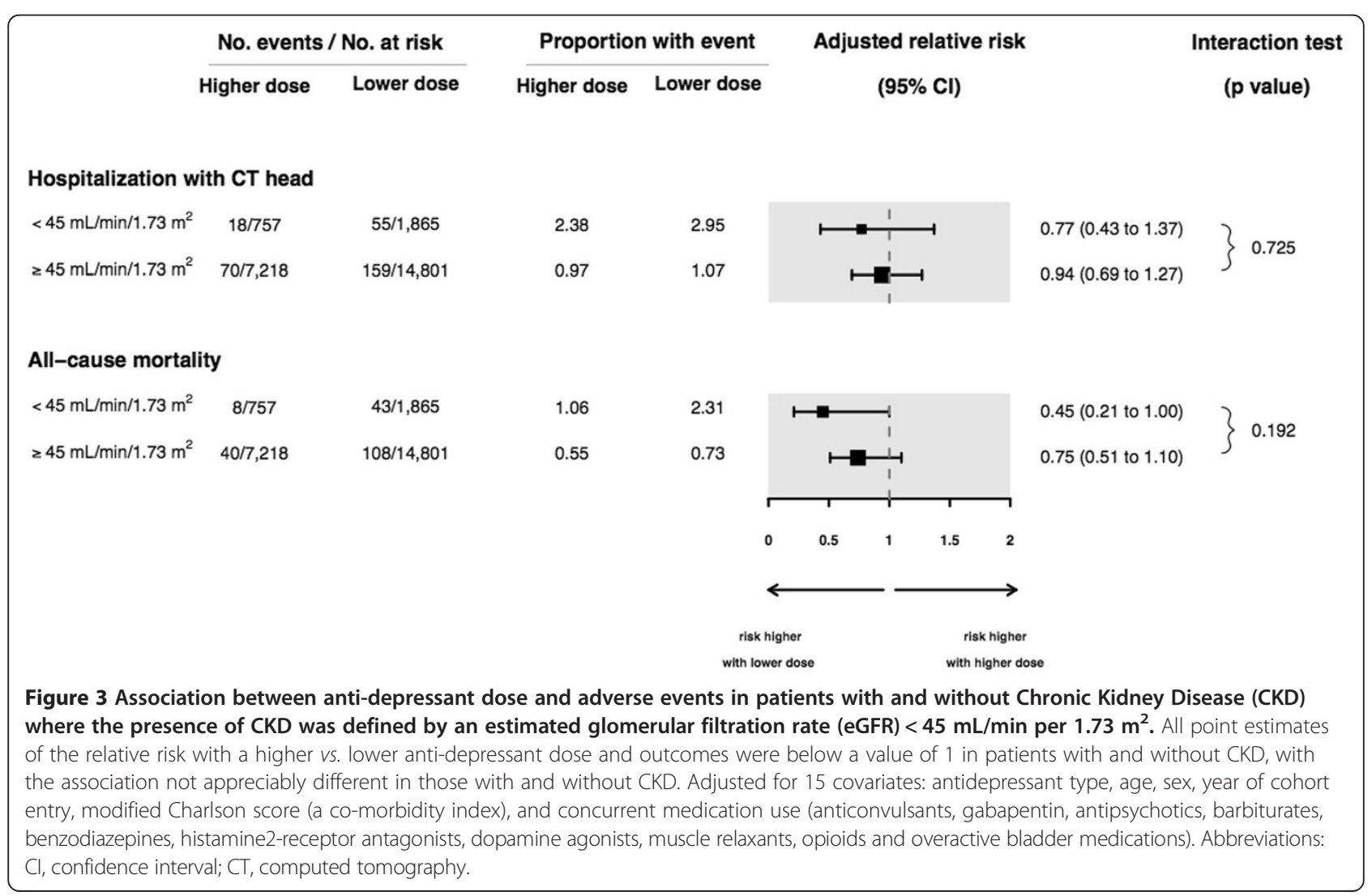


study is the first to examine the clinical consequences of failing to dose adjust anti-depressants in the setting of moderate CKD at the population level. There is a need to determine if drug dosing decisions based on pharmacokinetic data influence real practice outcomes. The lower risk of death we observed with higher doses of anti-depressant was contrary to our hypothesis. It is possible the association relates to unmeasured confounding between the two dosing groups. It is also possible that higher $v$ s. lower doses of anti-depressants are more efficacious in treating depression and improve survival. Inadequately treated depression can increase mortality risk through nonadherence to medications and health care appointments, poor nutrition, lack of social support, increased inflammation and compromised immunity [37-40]. Examining the causes of death such as suicide or withdrawal of care in this context would be useful in future studies, as such information was not reliable in our data sources.

With respect to patient safety, if concerns remain about the use of certain anti-depressants in patients with moderate $C K D$, a reasonable alternative is to prescribe an anti-depressant such as fluoxetine where the pharmacokinetics are not altered by the presence of CKD. Observational data also suggests that this anti-depressant is well tolerated by patients with CKD [14].

Our study has several strengths. The use of Ontario's broadly inclusive healthcare databases provided us with a large representative sample. The data was complete, drug dose and outcomes were accurately recorded, and patient loss to follow-up was minimal (emigration in our region is less than $1 \%$ per year) [41].

Our study has several limitations. The similarity of measured patient baseline characteristics in our two anti-depressant dose groups helped reduced concerns about the influence of confounding. The concern over residual confounding was also reduced by the lack of substantial change in the observed association after adjustment for multiple potential confounders. However, as mentioned, as in any observational study the possibility of unmeasured confounding can never be completely eliminated. We knew the anti-depressant was dispensed by a pharmacy but had no information on compliance. Future studies should include more patients with very low levels of eGFR (i.e. $<30 \mathrm{~mL} / \mathrm{min}$ per $1.73 \mathrm{~m}^{2}$ ), and should also collect body weight so that eGFR can also be expressed in $\mathrm{mL} / \mathrm{min}$. Our primary outcome was assessed retrospectively using existing healthcare database records and relied on urgent neuroimaging as a proxy for the diagnosis of delirium, which is an insensitive method to identify important changes in cognition. Rather, if resources allow for it, a well-designed prospective study with independent outcome adjudication would more precisely capture benefits and risks associated with initiating a higher vs. lower anti-depressant dose.

\section{Conclusion}

In this study which used large healthcare administrative databases, contrary to our hypothesis we failed to observe an association between initiation of a study antidepressant at a higher dose and a higher risk of two adverse outcomes in older adults with moderate CKD.

\section{Additional file}

Additional file 1: Figure S1. Patient Selection. Table S1. Checklist of Recommendations for Reporting of Observational Studies Using the STROBE Guidelines. Table S2. Coding Definitions for Demographics, Comorbid Conditions and Outcomes.

\section{Competing interests}

The authors declare that they have no relevant financial interests. The Institute for Clinical Evaluative Sciences (ICES) is a non-profit research corporation funded by an annual grant from the Ontario Ministry of Health and Long-Term Care (MOHLTC). The research was conducted at the ICES Western facility, which receives financial support from the Academic Medical Organization of Southwestern Ontario, the Schulich School of Medicine and Dentistry at Western University and the Lawson Health Research Institute. The opinions, results and conclusions are those of the authors and are independent from the funding sources. No endorsement by ICES or the Ontario MOHLTC is intended or should be inferred.

\section{Authors' contributions}

VD drafted the manuscript and performed literature reviews. SD carried out and supervised the statistical analyses. JF also aided in preparing the manuscript and data analysis. SJ aided in planning and carrying out analyses. TG, ZH, AJ and MW aided in manuscript preparation, study coordination, and statistical modeling. SS and DT aided in study design, research methodology and interpretation of data. AG conceived of the study, and participated in its design, coordination and manuscript preparation. All authors read and approved the final manuscript.

\section{Acknowledgements}

We thank Brogan Inc, Ottawa, for use of its Drug Product and Therapeutic Class Database, Gamma Dynacare for use of the outpatient laboratory database and the team at London Health Sciences Centre, St. Joseph's Health Care, and the Thames Valley Hospitals for providing access to the Cerner laboratory database. We thank Ms. Lihua Li for her help with the graphs and members of the provincial ICES Kidney Dialysis and

Transplantation Program (www.ices.on.ca) for their support of this study.

\section{Author details}

${ }^{1}$ Schulich School of Medicine, Western University, London, Canada. ${ }^{2}$ Division of Nephrology, Western University, London, Ontario, Canada. ${ }^{3}$ Department of Epidemiology and Biostatistics, Western University, London, Ontario, Canada. ${ }^{4}$ Institute for Clinical Evaluative Sciences, Ontario, Canada. ${ }^{5}$ Leslie Dan Faculty of Pharmacy, University of Toronto, Toronto, Ontario, Canada. ${ }^{6}$ Keenan Research Centre, Li Ka Shing Knowledge Institute, Toronto, Ontario, Canada. ${ }^{7}$ Division of Nephrology, University of Toronto, Toronto, Ontario, Canada. ${ }^{8}$ London Kidney Clinical Research Unit, Room ELL-101, London Health Sciences Centre, 800 Commissioners Road East, London, Ontario N6A 4G5, Canada.

Received: 6 January 2014 Accepted: 1 May 2014 Published: 10 May 2014

\section{References}

1. Wiese BS: Geriatric depression: The use of antidepressants in the ederly. BC Med J 2011, 53(7):341-347.

2. Gunnell D, Ashby D: Antidepressants and suicide: what is the balance of benefit and harm. BMJ (Clinical research ed) 2004, 329(7456):34-38. doi:10.1136/bmj.329.7456.34. 
3. Exeter D, Robinson E, Wheeler A: Antidepressant dispensing trends in New Zealand between 2004 and 2007. Aust N Z J Psychiatry 2009, 43(12):1131-1140. doi:10.3109/00048670903279879.

4. Moore M, Yuen HM, Dunn N, Mullee MA, Maskell J, Kendrick T: Explaining the rise in antidepressant prescribing: a descriptive study using the general practice research database. BMJ 2009, 339(b39999). doi:10.1136/ bmj.b3999.

5. Austin PC, Ph D, Upshur REG, Sc M: Use of Antidepressants Among Elderly Subjects: Trends and Contributing Factors. Am J Psychiatry 2000, 157:360-367.

6. Nagler EV, Webster AC, Vanholder R, Zoccali C: Antidepressants for depression in stage 3-5 chronic kidney disease: a systematic review of pharmacokinetics, efficacy and safety with recommendations by European Renal Best Practice (ERBP). Nephrol Dial Transplant 2012, 27(10):3736-3745. doi:10.1093/ndt/gfs295.

7. Smith GC, Clarke DM, Handrinos D, Trauer T: Adverse reactions to antidepressants in consultation-liaison psychiatry inpatients. Psychosomatics 2002, 43(3):228-33. doi:10.1176/appi.psy.43.3.228.

8. Dormann H, Sonst A, Müller F, Vogler R, Patapovas A, Pfistermeister B, Plank-Kiegele B, Kirchner M, Hartmann N, Bürkle T, Maas R: Adverse drug events in older patients admitted as an emergency: the role of potentially inappropriate medication in elderly people (PRISCUS). Dtsch Arztebl Int 2013, 110(13):213-9. doi:10.3238/arztebl.2013.0213.

9. Routledge PA, O'Mahony MS, Woodhouse KW: Adverse drug reactions in elderly patients. Br J Clin Pharmacol 2003, 57(2):121-126. doi:10.1046/j.13652125.2003.01875.x

10. Group, KDIGO (KDIGO) CW: KDIGO: Clinical Practice Guideline for the Evaluation and Management of Chronic Kidney Disease. Kidney Int Supp/ 2012, 2013(3):1-150.

11. Schaeffner ES, Ebert N, Delanaye P, Frei U, Gaedeke J, Jakob O, Kuhlmann MK, Schuchardt M, Tolle M, Ziebig R, van der Giet M, Martus P: Two novel equations to estimate kidney function in persons aged 70 years or older. Ann Intern Med 2013, 157(7):471-481.

12. Cohen LM, Tessier EG, Germain MJ, Levy NB: Update on psychotropic medication use in renal disease. Psychosomatics 2004, 45(1):34-48. doi:10.1176/appi.psy.45.1.34.

13. Crone CC, Gabriel GM: Treatment of anxiety and depression pharmacokinetic considerations. Clin Pharmacokinet 2004, 43(6):361-394.

14. Baghdady NT, Banik S, Swartz SA, Mclntyre RS: Psychotropic drugs and renal failure: translating the evidence for clinical practice. Adv Ther 2009, 26(4):404-424. doi:10.1007/s12325-009-0021-x.

15. Bailer U, Fischer P, Küfferle B, Stastny J, Kasper S: Occurrence of mirtazapine-induced delirium in organic brain disorder. Int Clin Psychopharmacol 2000, 15(4):239-243. Available at: http://www.ncbi.nlm.nih. gov/pubmed/10954066.

16. Alexander J, Nillsen A: Venlafaxine-induced delirium. Aust N Z J Psychiatry 2011, 45(7):606. doi:10.3109/00048674.2011.567968.

17. Chuang Y-F, Chiu Y-L, Hwang T-J, Chu T-S: Delirium and multiple electrolyte abnormalities associated with high dose paroxetine exposure. Psychiatry Clin Neurosci 2006, 60(5):642-643. doi:10.1111/j.1440-1819.2006.01574.x

18. Wakeno M, Okugawa G, Takekita Y, Kato M, Fukuda T, Yamashita M, Hosoi Y, Azuma J: Delirium associated with paroxetine in an elderly depressive patient: a case report. Pharmacopsychiatry 2007, 40(5):199-200. doi:10.1055/s-2007-985882

19. UpToDate V21.1. Mirtazapine: Drug Information. http://www-uptodate- com proxy2.lib.uwo.ca/contents/mirtazapine-drug- information?source=search result\&search=mirtazapine\&selectedTitle=1 49. Accessed on: 5-11-2013.

20. UpToDate V21.1. Venlafaxine: Drug Information. http://www-uptodate- com. proxy2.lib.uwo.ca/contents/venlafaxine-drug- information?source=search_ result\&search=venlafaxine\&selectedTitle=1 96. Accessed on: 5-11-2013.

21. UpToDate V21.1. Paroxetine: Drug Information. http://www-uptodate- com. proxy2.lib.uwo.ca/contents/paroxetine-drug- information?source=search_ result\&search $=$ paroxetine\&selectedTitle $=1 \sim 127$. Accessed on 5-11-13.

22. Paxil [product monograph]: Compendium of Pharmaceuticals and Specialties. Ottawa, Canada: Canadian Pharmacists Association; 2008:1645-1655.

23. Effexor [product monograph]: Compendium of Pharmaceuticals and Specialties. Ottawa, Canada: Canadian Pharmacists Association; 2008:766-776.

24. Remeron [product monograph]: Compendium of Pharmaceuticals and Specialties. Ottawa, Canada: Canadian Pharmacists Association; 2008:1908-1911.

25. Canada S: Population by sex and age group, by province and territory. Ottawa: Statistics Canada; 2012. Available at: http://www.statcan.gc.ca/tablestableaux/sum-som/l01/cst01/demo31a-eng.htm.
26. Von Elm E, Altman DG, Egger M, Pocock SJ, Gøtzsche PC, Vandenbroucke JP: The Strengthening the Reporting of Observational Studies in Epidemiology (STROBE) statement: guidelines for reporting observational studies. J Clin Epidemio/ 2008, 61(4):344-349. doi:10.1016/j. jclinepi.2007.11.008.

27. Levy AR, O'Brien BJ, Sellors C, Grootendorst P, Willison D: Coding accuracy of administrative drug claims in the Ontario Drug Benefit database. Can J Clin Pharmacol 2003, 10(2):67-71. Available at: http://www.ncbi.nlm.nih. gov/pubmed/12879144.

28. Gandhi S, Shariff SZ, Beyea MM, Weir MA, Hands T, Kearns G, Garg AX: Identifying geographical regions serviced by hospitals to assess laboratory-based outcomes. BMJ open 2013, 3(1):1-6. doi:10.1136/ bmjopen-2012-001921.

29. Zhao YY, Weir MA, Manno M, Cordy P, Gomes T, Hackam DG, Juurlink DN, Mamdani M, Moist L, Parikh CR, Paterson JM, Wald R, Yao Z, Garg AX: New fibrate use and acute renal outcomes in elderly adults: a populationbased study. Ann Intern Med 2012, 156(8):560-569.

30. Shih AW, Weir MA, Clemens KK, Yao Z, Gomes T, Mamdani MM, Juurlink DN, Hird A, Hodsman A, Parikh CR, Wald R, Cadarette SM, Garg AX: Oral bisphosphonate use in the elderly is not associated with acute kidney injury. Kidney Int 2012, 82(8):903-908.

31. Lam NN, Weir MA, Yao Z, Blake PG, Beyea MM, Gomes T, Gandhi S, Mamdani M, Wald R, Parikh CR, Hackam DG, Garg AX: Risk of acute kidney injury from oral acyclovir: A population-based study. Am J Kidney Dis 2013, 61(5):723-729.

32. Fleet JL, Dixon SN, Shariff SZ, Quinn RR, Nash DM, Harel Z, Garg AX: Detecting chronic kidney disease in population-based administrative databases using an algorithm of hospital encounter and physician claim codes. BMC Nephrol 2013, 14:81.

33. Mitsch AL: Antidepressant adverse drug reactions in older adults: Implications for RNs and APNs. Geriatric nursing (New York, NY) 2012, 34(1):53-61.

34. Williams J, Young W: A summary of studies on the quality of health care administrative databases in Canada. Ottawa: Canadian Medical Association; 1996:339-45.

35. Jha P, Deboer D, Sykora K, Naylor C: Characteristics and mortality outcomes of thrombolysis trial participants and nonparticipants: a population-based comparison. J Am Coll Cardiol 1996, 27:1335-1342.

36. Austin P: Using the standardized difference to compare the prevalence of a binary variable between Two groups in observational research. Communication in Statistics - Simulation and Computation 2009, 38:1228-1234.

37. Empana JP, Sykes DH, Luc G, Juhan-Vague I, Arveiller D, Ferrieres J, Amouyel P, Bingham A, Montaye $M$, Ruidavets JB, Haas B, Evans A, Jouven X, Ducimetiere P, PRIME Study Group: Contributions of depressive mood and circulating inflammatory markers to coronary heart disease in healthy European men: the Prospective Epidemiological Study of Myocardial Infarction (PRIME). Circulation 2005, 111(18):2299-2305. doi:10.1161/01. CIR.0000164203.54111.AE.

38. Barefoot JC, Burg MM, Carney RM, Cornell CE, Czajkowski SM, Freedland KE, Hosking JD, Khatri P, Pitula CR, Sheps D: Aspects of social support associated with depression at hospitalization and follow-up assessment among cardiac patients. J Cardpulm Rehabil 2003, 23(6):404-412. Available at: http://www.ncbi.nlm.nih.gov/pubmed/14646786.

39. Bonnet F, Irving K, Terra J-L, Nony P, Berthezène F, Moulin P: Anxiety and depression are associated with unhealthy lifestyle in patients at risk of cardiovascular disease. Atherosclerosis 2005, 178(2):339-344. doi:10.1016/j. atherosclerosis.2004.08.035.

40. Koo JR, Yoon JW, Kim SG, Lee YK, Oh KH, Kim GH, Kim HJ, Chae DW, Noh JW, Lee SK, Son BK: Association of depression with malnutrition in chronic hemodialysis patients. Am J Kidney Dis 2003, 41(5):1037-1042. Available at: http://www.ncbi.nlm.nih.gov/pubmed/12722038.

41. Ontario Ministry of Finance: Ontario Population Projections 2011-2036: Ontario and Its 49 Census Divisions. Toronto: Queen's Printer for Ontario; 2012. Ref Type: Report.

doi:10.1186/1471-2369-15-79

Cite this article as: Dev et al.: Higher anti-depressant dose and major adverse outcomes in moderate chronic kidney disease: a retrospective population-based study. BMC Nephrology 2014 15:79. 